\title{
ACCULTURATION IN THE DISCOURSE OF IMMIGRANTS AND RECEIVING COMMUNITY MEMBERS. RESULTS FROM A CROSS-NATIONAL QUALITATIVE STUDY
}

\section{This is the author's manuscript}

Original Citation:

\section{Availability:}

This version is available http://hdl.handle.net/2318/1660439

since 2019-07-05T14:19:18Z

Published version:

DOI:10.1037/ort0000325

Terms of use:

Open Access

Anyone can freely access the full text of works made available as "Open Access". Works made available under a Creative Commons license can be used according to the terms and conditions of said license. Use of all other works requires consent of the right holder (author or publisher) if not exempted from copyright protection by the applicable law. 


\title{
Acculturation in the discourse of immigrants and receiving community members.
}

\section{Results from a cross-national qualitative study.}

\begin{abstract}
This study explores the bidirectional and interactional process of acculturation from the perspectives of immigrants and receiving community members (RCMs). Our aim was to understand the experiences and interactions of different ethno-cultural groups and their impact on the functioning and dynamics of multicultural communities. We conducted a cross-national, cross-cultural study of acculturation processes, using interviews collected across two countries (Italy: urban regions of Torino and Lecce; U.S.: Baltimore/Washington corridor) and three distinct groups of immigrants - Moroccans and Albanians in Italy and Latin Americans in the U.S. - and RCMs in Italy and U.S. Findings show that acculturation is a complex, situated, and dynamic process, and is generally conceived as an unbalanced and individual process of accommodation, which expects the immigrant alone to adapt to the new context. The boundaries among traditionally explored acculturation strategies were blurred and while integration was the most frequently discussed strategy, it often referenced a "soft" assimilation, limited mostly to public domains. Some differences emerged between ethnic groups and generation of immigration as well as among RCMs who differed by level of contact with immigrants. The need for more flexible models and for a critical perspective on acculturation is discussed.
\end{abstract}

Public policy relevance statement: The reciprocal adaptation between immigrants and receiving community members is a complex and situated process, where a variety of experiences and expectancies from both groups come into play and a greater effort is required by immigrants. The study suggests that immigration policies should avoid conceiving of immigrants as one homogeneous category and that more effective policies and practices to achieve integration should be sensitive to the cultural, ethnic, and power differences, both within and between immigrants and receiving community members. 


\section{Acculturation in the discourse of immigrants and receiving community members:}

\section{Results from a cross-national qualitative study}

The United Nations estimated that by 2015 , over $3 \%$ of the world population, some 244 million people, lived outside their country of origin. While some $70 \%$ are said to have migrated voluntarily for economic reasons, nearly $25 \%$ could be considered involuntarily displaced by conflict, violence, and other human rights violations (UNFPA, 2015). When immigrants arrive, they bring a rich array of values, practices, and identities that impact the receiving community at various levels (Schwartz, Unger, Zamboanga, \& Szapocznik, 2010). The arrival of newcomers has long been met with mixed reactions, with places like the U.S. having a long complicated history of both being built by immigrants while it has simultaneously, across its history, placed differential restrictions on immigrants depending on nation of origin, educational and economic status, and reasons for immigration. Italy, long a country with more outmigration than in, has in recent years seen a steep increase in officially sanctioned and non-sanctioned immigration from people seeking both economic advantages and protection from natural and manmade dangers. Both Italy and the U.S. are currently engaged in contentious debate regarding the role, risks and benefits, inclusion and exclusion of immigrant populations vis-à-vis the larger receiving community.

Local communities (i.e., the settings of everyday living; Bronfenbrenner \& Morris, 1998) are the places where the complex dynamic of multicultural contacts between immigrants and receiving community members usually takes place (Prilleltensky, 2008; Sabatier, 2008; Ward, Fox, Wilson, Stuart \& Kus, 2010). The quality of contact is related, among other factors, to the constant dialogue between immigrants' cultural attitudes and behaviors (often not entirely free) and receiving members' expectations. These factors, along with related and reciprocal acculturation attitudes, frame the ways intercultural relationships are created and interpreted inside a community (Bourhis, Moise, Perreault, \& 
Senecal, 1997; Navas, García, Sánchez, Rojas, Pumares \& Fernández, 2005). Ultimately, these attitudes - made of values, norms, mutuality, co-operation, and identification - are merged and enacted in the physical dimension of shared spaces, where differences in cultural and ethnic origins often mirror the existence of other differences, such as in social status and power (Dixon \& Levine, 2012; Smith, 2008; Tseng \& Yoshikawa, 2008). Thus, all of these influences should be taken into account when studying social groups.

Berry's (2005) distinction between 'dominant' and 'non-dominant' cultural groups is an attempt to elaborate on the relative power that affects inter-ethnic relations. This power differential is also echoed in social science literature on acculturation, as such work typically focuses on the acculturation of immigrants and attitudes of receiving communities towards immigrants' acculturation, rather than on reciprocal acculturation strategies and expectancies (Bowskill, Lyons, \& Coyle, 2007; Yakushko \& Morgan-Consoli, 2014). Despite many examples of the receiving community holding much more power, the dynamics most often reflected in mainstream media concern receiving community member's fears of losing power - be it cultural, sociopolitical, or economic - to their society's newcomers (i.e., realistic and symbolic threat; Stephan \& Stephan, 2000).

On these bases, the present study explores the bi-directional and interactive process of acculturation from the perspectives of both immigrant and receiving community members (henceforth RCMs). Our aim was to understand the experiences and interactions of different ethno-cultural groups and their impact on the functioning and dynamics of multicultural communities. To do so, we conducted a cross-national, cross-cultural study of acculturation processes, collecting interviews across two countries (Italy: urban Torino and Lecce; U.S.: Baltimore/Washington corridor). The study involved immigrants - Moroccans and Albanians in Italy and Latin Americans in the U.S. - and RCMs in Italy and U.S.

\section{Acculturation and multicultural societies}


Acculturation refers to the multidimensional changes people undergo through crosscultural transitions. Theories in the field have evolved to form a consistent framework that encompasses multiple interlacing aspects of acculturation - attitudes, behavioral repertoires, life domains - with an increasing emphasis on this as a bi-dimensional and interactive perspective (e.g., Berry, 2006; Bourhis et al., 1997; Navas et al., 2005). Berry (2006) posits that from the intersection of the two motivational drives - one's willingness to maintain one's cultural heritage and one's interest in participating in the receiving (or newly received) community - four behavioral acculturation orientations result: integration, maintenance of cultural heritage and adoption of new cultural traits; assimilation, relinquishment of cultural heritage and replacement with new cultural traits; separation, maintenance of cultural heritage and refusal to adopt new cultural traits; and marginalization, refusal of both heritage and new cultural traits. As a reciprocal process, acculturation affects members of each of two or more cultural groups, as each adapts to the other's presence (Berry, 2006). In their Interactive Acculturation Model (IAM), Bourhis and colleagues (1997) detail how the acculturation orientations held by immigrant groups and the immigration ideologies shared by receiving community members can match or mismatch. Particularly, the mismatch can have negative psychological (e.g., lowered self-esteem in immigrants, Berry, 1970; Bourhis et al. 1997), as well as social (e.g., higher in-group bias, less acceptance, and more perceived threat in both groups, Rohmann, Florack \& Piontkowski, 2006; Rohmann, Piontkowski \& van Randenborgh, 2008; Zagefka \& Brown, 2002; Zagefka, González \& Brown, 2011) consequences.

Several studies show that immigrants tend to prefer integration whereas RCMs commonly prefer assimilation. Moreover, RCMs tend to underestimate immigrants' willingness to participate in building a pluralistic community, overemphasizing immigrants' tendency to prioritize cultural maintenance (Arends-Toth \& Van de Vijver, 
2003; Pfafferott \& Brown, 2006; Rohmann et al., 2006; Zagefka \& Brown, 2002).

Acculturation strategies and expectancies can also vary across life domains as different settings affect acculturation and exert different adaptive requirements or acculturative pressures (Salo \& Birman, 2015). For example, RCMs may accept and foster maintenance of immigrants' traditions in a private context (e.g., within families, values/belief systems) while simultaneously expecting and even demanding adaptation to the receiving culture in public domains (e.g., work, school, other shared spaces; Buckingham, 2017; Navas, et al., 2005). Some studies show a clear preference for integration among immigrants in public domains whereas they consider separation more suitable in private ones (e.g., Mancini \& Bottura, 2014; Navas, Rojas, García, \& Pumares, 2007; Taylor \& Lambert, 1996).

Only recently, empirical evidence highlighted that acculturation strategies and expectancies can also vary among generations. On the one hand, cultural adaptation can be more difficult for those who arrive as adults to a different country, as they have already established identities and/or less educational and socialization opportunities (e.g., Cheung, Chudek \& Heine, 2011; Pumariega \& Rothe, 2010); on the other hand, RCMs seem to be more tolerant towards $1^{\text {st }}$ generation immigrants who want to maintain aspects of their cultural background than towards that same desire in $2^{\text {nd }}$ generation immigrants (Kunst $\&$ Sam, 2013; 2014; Matera, Stefanile \& Brown, 2015). Acculturation research has also shown that the challenges posed to identity vary across $1^{\text {st }}$ and $2^{\text {nd }}$ gen. immigrants and that the negotiation of identity can be especially problematic for the latter because they are torn between two cultures (Phinney \& Rosenthal, 1992). Despite seemingly 'commonsense' expectations of greater ease, depending on the attitudes of the receiving society, children of immigrants are unlikely to undergo straightforward integration or to be directly assimilated into the host context (Portes, Fernandez-Kelly \& Haller, 2005); they are rather likely to develop their identity by combining their ethnic difference, social networks, bilingualism, 
and transnationalism in a multitude of ways (Buckingham \& Brodsky, 2015).

Finally, since acculturation processes are embedded in interethnic relationships, the scholarly study of effects of intergroup contact on acculturation is also worth reviewing. Allport (1954) originally posited that contact would facilitate the acquaintance with the outgroup, and this, in turn, would reduce prejudice. This theory has inspired a huge amount of theoretical and empirical work over the years. A meta-analysis (Pettigrew \& Tropp, 2006; 2008) highlighted that intergroup contact can significantly reduce prejudice in a variety of situations, and it also highlighted the importance of taking into account the contextual conditions that make intergroup contact work. Moreover, Pettigrew and Tropp $(2006 ; 2008)$ underlined the need to reformulate the intergroup contact theory so as to consider the mediational role played, on the one hand, by anxiety triggered by intergroup contact, and on the other, by empathy and perspective taking. Since prejudice and discrimination can deeply affect intergroup relations, acculturation process studies would benefit from the understanding of such dynamics.

\section{Current work}

The current research aimed to investigate the different facets of acculturation from the points of view of both immigrants and RCMs, thus capturing the complexity and variability of their simultaneous acculturative process. Specifically, we interviewed three groups of immigrants settled in two fairly different receiving contexts (Moroccans and Albanians settled in Italy and Latin Americans settled in the United States). Immigrants and RCM participants in these different cultural contexts were also distinguished by their generation of immigration ( $1^{\text {st }}$ vs. $2^{\text {nd }}$ generation) and self-reported frequency of intergroup contact (high vs. low contact) respectively.

The study reported herein presents results addressing the following key questions: How do immigrants and RCMs face the acculturation process that is occurring in their 
cultural contexts? How do immigrants understand their adaptation to their new community? How do RCMs view and interpret the ways in which immigrants acculturate?

Since the acculturation process varies across the variables discussed above, we paid attention to differences across life domains (e.g., family, friendships, work, etc.), $1^{\text {st }}$ and $2^{\text {nd }}$ gen. immigrants, low and high contact RCMs, and across national/geographic settings.

\section{Study Context}

\section{Italy Immigration Context ${ }^{1}$}

Although Italy has been experiencing immigration since the 1990's, the public debate still considers immigration a recent phenomenon and, despite its geographical position as a Mediterranean gateway, there are no consistent Italian policies covering the integration of immigrants. Many different - sometimes contradicting - immigration laws have been adopted in the course of time, but none of them consider the ongoing cultural pluralization of Italy in an overall and long-term perspective. Overall, Italy can be considered "a country without an established model of integration or pluralism" (Allievi, 2014, p.724).

Current national migration policies rest on flux control; immigrating to the country without permission is considered a crime. Because of the Italian nationality law, it is difficult to lose one's identification as an immigrant, even across generations and distinctions among the generations of immigration may have less meaning. The Italian law is based on ius sanguinis (right of blood), according to which citizenship is automatically acquired only by birth to an Italian parent. Individuals born in Italy to non-Italian parents have one year from the time they reach majority age to apply for citizenship. If they miss this period, the law considers them as new arrivals to the country. Immigrants can obtain Italian citizenship after two years of marriage with an Italian citizen or by continuously

\footnotetext{
${ }^{1}$ This research was conceived and all data collected by 2013, before the Syrian refugee crisis had begun. However, the prior ten plus years of Afghan and Iraq hostilities, as well as countless crises across Africa had already resulted in pronounced upticks in immigration to Italy and other European countries.
} 
residing or working in Italy for at least 4 (for European Union -EU- citizens) or 10 (for nonEU citizens) years. This legislative framework produces an inaccurate picture of the immigrants-nationals ratio whereby a very low rate of naturalization (e.g., to date from 2016 only $4 \%$ of all immigrants to Italy obtained citizenship, www.istat.it, n.d.) leads to the inclusion of multiple generations born to immigrant families in the immigration count.

At present, there are reported to be about 5 million immigrants from over 190 different countries (plus approximately 326,000 persons currently living in the shadow;

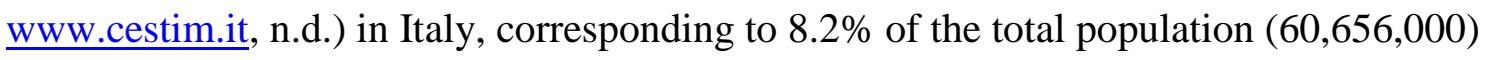
(Immigration Statistical Report, 2015). Among these are 3.8 million people from nonEuropean Union countries, especially from Morocco and Albania with 525 and 503 thousand, respectively, settled in Italy. Moroccans and Albanians are also among the most longstanding settlements of foreigners and, consequently, some of the ethno-cultural groups with more than one (and often many more) generation of immigrants in Italy. Almost $60 \%$ of immigrants live in the industrialized northern-center of the country (www.istat.it, n.d.).

\section{U.S. Immigration Context}

Currently, there are approximately 50 million first generation immigrants in the United States, and approximately one out of every five people living in the United States today is a $1^{\text {st }}$ or $2^{\text {nd }}$ generation immigrant (United Nations Department of Economic and Social Affairs, Population Division, 2016). Pew Research Center estimates 11.3 million of these immigrants lack authorization to reside in the country as of 2016, slightly less than the estimated 12.7 million person peak in 2007 (Pew, 2015).

Approximately half of the foreign-born population in the U.S. is of Latin American origin (Acosta \& De la Cruz, 2011; Cook-Martín \& FitzGerald, 2010), a nearly nine-fold increase since 1960. Historically and today, Mexican-origin immigrants are the largest 
Latinx ${ }^{2}$ ethnic group in the U.S.; however, the origins of the nation's Latinx population has diversified over time (Passel, Cohn \& Gonzalez-Barrera, 2012). In the Mid-Atlantic region, where this research was done, the countries of origin of Latinx immigrants include primarily immigrants from Mexico, Central America (e.g., El Salvador, Guatemala), as well as northern countries of South America (e.g., Peru).

Immigration has been a heated topic across United States history and is consistently in the forefront of political discussions, and this has perhaps only increased since the 2016 elections. In a recent representative national poll conducted by the Pew Research Center, $37 \%$ of Americans indicated that they believed that immigrants were worsening the U.S. while $45 \%$ reported believing that immigrants were improving the country in the long run (Krogstad, 2015). Despite constant debate over federal immigration policies, U.S. policies can be described as coming from both an assimilation ideology (i.e., the government can intervene with some private values and practices of immigrants such as linguistic, cultural, religious practices) and a civic ideology (i.e., government cannot mandate private values and practices but at the same time government should not financially or socially support the private activities of immigrant communities; Bourhis et al., 1997). Many states have enacted their own policies to restrict or support the participation of immigrants in local receiving communities, and consequently, the context of immigration is very different across the U.S. and even within the Mid-Atlantic region as well.

\section{Method}

\section{Participants}

From each of the three study regions, 59 to $80^{3}$ people participated in a 1-2 hour, in-

\footnotetext{
${ }^{2}$ The term "Latinx" is utilized to move beyond binary gender (male/female) when referencing people with Latin American origin.

${ }^{3}$ The goal was to recruit and interview 60 participants in each region $\left(151^{\text {st }}\right.$ gen immigrants, $152^{\text {nd }}$ gen immigrants, 15 low contact RCMs, 15 high contact RCMs). While purposive sampling was used to meet these goals, because recruitment was often done simultaneously by multiple interviewers, and actual participant demographics were not known until the interview was underway, some participant groups in some settings were oversampled. One setting decided to collect data until all
} 
person interview, for a total of 199 participants ${ }^{4}$. Of these, one half were RCMs (i.e., $3^{\text {rd }}$ generation or more receiving community members), and the other half were nearly equally mixed between 1 st and 2nd generation (henceforth $1 \mathrm{G}$ and $2 \mathrm{G}$ ) immigrants. All $1 \mathrm{G}$ participants had lived in Italy or the U.S. for at least 5 years and were conversant in Italian or English (depending on setting). All 2G participants were either born in the receiving community country or had emigrated before age 6. All 70 Italian-born (Torino: 40, Lecce: 30) and 30 U.S.-born RCMs had lived in their respective country for at least 3 generations. In Torino, immigrant participants were Moroccan and in Lecce, Albanian. In the Baltimore/DC sample, the $1 \mathrm{G}$ participants were Latinx immigrants (4 from Peru, 1 each from Bolivia, Columbia, Cuba, the Dominican Republic, Ecuador, El Salvador, Guatemala, Mexico, Nicaragua, Panama, and Puerto Rico ${ }^{5}$ ) and 15 children of Latinx immigrants (4 of Salvadoran origins, 3 of Mexican origins, 1 each of Chilean, Cuban, Dominican Republic, Guatemalan, Panamanian, and Peruvian origins, and 2 with mixed Latin American origin). Half of each RCM group self-identified as having a high amount of contact (HC) with immigrant groups and the other half self-reported low contact (LC) using an initial screening question ${ }^{6}$. All Italian participants self-identified as White. Of the U.S. receiving community sample who had high contact with immigrants, $60 \%$ identified as White, $20 \%$ as Latinx, $13 \%$ as Black, and $6 \%$ as multiracial; of those who reported as low contact, $53 \%$ identified as White and $47 \%$ as Black. All participants were at least 18 years of age and overall the participants consisted of slightly more women than men (see Table 1).

\section{INSERT TABLE 1 ABOUT HERE}

participant groups were equal. Once collected, all data was analyzed. In one setting, a post data collection technology failure led to the loss of one participant's data.

${ }^{4}$ Response/refusal rates were not recorded for fear of making $1 \mathrm{G}$ immigrants, in particular, uncomfortable.

${ }^{5}$ Puerto Rico while a territory of the United States is culturally and linguistically distinct and without full rights granted to U.S.-born citizens in a state. Thus, we allowed Puerto Rican participants to self-select whether they identified as immigrants or U.S.-born receiving community members.

${ }^{6}$ In Lecce there were $14 \mathrm{HC}$ and 16 LC. RCM participants were asked whether they considered themselves to have a lot or very little contact with people who were immigrants. 


\section{Data Collection}

A qualitative method was adopted as the best way to delve into the complexity of acculturation in a cross-national and cross-cultural context. Participants were recruited from public settings (e.g., ethnic heritage festival, soccer matches, laundromats, public gardens) and via snowball sampling, word-of-mouth, and fliers. All participants were provided with oral and written informed consent information and gave oral consent; a waiver of written consent was granted to protect the confidentiality and anonymity of participants ${ }^{7}$. Audiorecorded interviews took place in public settings (e.g. libraries, community organizations, and parks), as well as university settings and private homes. Interviews were conducted between January 2012 and October 2013 by trained interviewers who followed a semi-structured interview guide and probed for additional information as appropriate. The interview grid touched upon a) demographics, b) international experience and exposure (e.g. Did you live in another country other than [country of origin] before you came to the U.S./Italy?; Have you ever lived in another country?; Do you have any close relatives who were born in a country other than the U.S./Italy?), c) family constellation and immigration history (e.g. What do you know about your family's immigration history?; Are there any members of your family who have immigrated to another country?; What made you decide to come to the U.S./Italy?), d) experiences with and e) attitudes towards immigrants and receiving community members (e.g. Do you spend time with people who were not born in the U.S.?; Do you think your relationships with U.S./Italy-born/non-U.S./non-Italy born friends and acquaintances are authentic?; Has your personal opinion of people born in the U.S./Italy changed since you've come to the U.S./Italy?) f) intergroup experiences (e.g. Do you feel like a guest in the U.S./Italy?; Do you think immigrants/non-immigrants have anything to gain/lose from interacting with each other?) The interview was designed to touch on parallel types of

\footnotetext{
${ }^{7}$ Similarly, immigration and citizen status was not asked to protect participants, although naturalized citizens often volunteered this information.
} 
experiences across the groups, while also accounting for obvious differences. For instance, while all immigrant participants were asked about their personal or familiar immigration experience, RCM members in the U.S. were asked what they knew, if anything, about their family's immigration history in the U.S., and RCMs in Italy, where all third generation participants were ethnic "Italians," were asked if anyone in their family had ever immigrated elsewhere. Interviews were conducted in Italian in Lecce and Torino, and in English in Baltimore/DC. ${ }^{8}$ Interviewers varied in education level, ethnicity, gender, and immigration status and although systematic review was not possible, there were no obvious patterns regarding characteristics of interviewers and those who volunteered to participate. Thus while the demographic positionalities of the interviewers no doubt may have an impact on participants, these varied relationships also added to the richness of the data and we were careful to utilize the varied positionalities of the research team members to further enrich the reflective processes involved in analysis. In Lecce, participants received nothing; in Torino they were offered a token of appreciation, consisting of either a shopping bag or pencils; in the U.S. they were paid $\$ 15$ for their time. The Ethics Committees/Institutional Review Boards of the involved universities approved the study protocol.

\section{Data Analysis}

Interviews were transcribed verbatim by the research team that collected them and checked for accuracy by researchers and research team members in their respective settings. Any identifying information was stripped from the final transcripts. The transcribed interviews were analyzed in the language of origin by each team using a shared thematic analysis approach that applied open and axial coding to generate iterative, emergent thematic categories (Strauss \& Corbin, 1990). This iterative coding framework

\footnotetext{
${ }^{8}$ This ability to speak the language of the receiving community was assumed to be a basic necessity for participants - and particularly $1^{\text {st }}$ gen. immigrants - to have the potential to have formed meaningful relations with the other groups being studied.
} 
was developed collaboratively across all three settings through successive approximations, with the goal of capturing the shared and unique content, cultural-context, themes, and processes related to the immigrant and receiving community experiences vis à vis their own and the other group. A working template was first developed in the interview language, then applied, expanded, and modified to fit the data in each context. While the U.S. based research team worked exclusively in English, the bilingual Italian team was translated their emergent codes and combined them with the U.S. team's work to create a final coding template that captured demographics and identifications, individual and community factors, concerns, experience, and attitudes. Final coding of each team's data was then conducted in the language of the interview using a research team approach in which general definitions and consensus was built among the entire group, and then coding was completed in pairs who came to consensus on each transcript. Memoing and research team meetings were used to keep the work of all coding teams parallel. Codes were entered into Atlas.Ti qualitative data analysis and management software. Analysis was conducted through parallel queries posed to both the U.S. and Italian data sets and explored through discussion both within and across research teams. Illustrative Italian data was translated into English for the purposes of cross team understanding and manuscript writing.

\section{Results}

In this section, we first focus on immigrants' understanding of their adaptation to the receiving society from both the Italian contexts (Moroccan and Albanian groups) and the U.S. context (Latinx). We then discuss the ways in which RCMs interpret how immigrants acculturate, considering their familiarity (degree of contact) with immigrant community members. Exemplar interview quotes are used to illustrate the findings. Participants are identified through their pseudonyms, birth country (Morocco, Albania, Latinx-origin, Italy or U.S.) generation of immigration ( $1 \mathrm{G}$ or $2 \mathrm{G})$, degree of contacts with immigrants for 
RCMs (HC, LC), gender, and age.

\section{The Acculturation Process from the Immigrants' Perspectives}

\section{Italian context.}

Integration on request: Losses and gains of identity strategies. When our interviewees talked about their situation in Italian society, they often used the term integration (integrazione). In theory, integration implies a mix between the original and receiving cultures and entails the search for a "third path" between the maintenance of cultural roots and their complete relinquishment. Indeed, both Albanians and Moroccans considered the maintenance of cultural roots to be an important value. Nevertheless, participants simultaneously reported that they felt required to assimilate in order to reach a full integration, so that a composite process emerged, in which the boundaries between integration and assimilation blur. Integration was thus interpreted as "assimilation on request", to be played out when needed, as well described by this $1 \mathrm{G}$ interviewee, "When I'm with Italians, I put my Italian brain on. And I already know which discourses they like and which can be interesting for them" (Youssef, Morocco, 1G, M, 30). From this perspective, at least for some of our participants, integration was meant as a passing strategy, a camouflaged assimilation, "Surely, you [immigrant] have to demonstrate that you are a regular person. That you have a different culture, but you are still a person .... It becomes difficult when immigrants behave differently than they are expected" (Oneda, Albania, 1G, F, 23).

In general, immigrants highlighted the key role of their own personal willingness and efforts to meet the demands of the receiving society. For the Albanians interviewees particularly, such efforts were mostly described in an individualistic perspective: they mostly referenced themselves, their personal experience and efforts. While on only a few occasions did they talk about their fellow Albanians settled in Italy, and almost never the 
support of fellow countrymen in pursuing integration.

Living in a foreign culture creates a variety of impacts on personal identity. On the one hand, dealing with a different culture, or even internalizing it, may induce a sense of identity loss. This sense of loss can become more salient when immigrants return to their country of origin, where they also feel that they are "losing an identity... I mean, the way of life has changed so far that even in my country I don't feel a real Moroccan" (Abida, Morocco, 1G, F, 42). This feeling of loss was especially apparent to the Moroccan $1 \mathrm{G}$ participants, while it was less relevant to Albanian $1 \mathrm{G}$ respondents. The latter seemed to be more critical of what they saw as some negative traits of their culture of origin, such as sexism and excessive traditionalism, and this critical attitude may compensate for the loss of valued aspects of their culture. Moreover, for some of them, there were also political reasons to leave Albania, which led them to view their decision to emigrate as an intentional act of discontinuity. On the other hand, immigrants' cultural integration may cause the boundaries of identity to widen so that multicultural, hyphenated, and cosmopolitan identities emerge. This shift was found more often among young Albanians, both $1 \mathrm{G}$ and $2 \mathrm{G}$ immigrants, who identified themselves as "world citizens":

I feel neither 100\% Albanian nor 100\% Italian. I'm a world citizen, somehow. I feel I'm richer than other people, as I know one more culture, one more language. All these things help me to interact with people. I think I would understand immigrants, were they Africans or Arabs, better than Italians could (Vera, Albania, 1G, F, 28).

Integration as engagement: Gains and losses. For most Moroccan 2G, integration seemed to be more a matter of being part of the receiving community than a matter of identity change. The key factors necessary for feeling integrated becoming a member of the receiving community appeared to be engaging in community, as a young man explained:

I feel more integrated than an Italian himself does, because I'm actually integrated after all. Integrated could mean to have a job, to have some friends, a home, to benefit from service. For me, integration is 
feeling part of a community (Amin, Morocco, 2G8, M, 24).

However, they also perceived the costs of such "integration," namely feeling estranged from their society of origin and being treated differently because of being born and brought up in a different culture. As this young man affirmed:

From family viewpoint, all the differences come out, because you were born and you have been living in Europe, they don't treat you as a guy living there [in Morocco]. When I'm 18 years old I can smoke a cigarette in front of my grandmother, and nobody else [can] do that [...] I don't think it is something more, indeed, it is something less. [...] You are allowed to do that because you grew up in a different context (Karim, Morocco, 2G, M, 18).

Both Moroccan and Albanian 2G immigrants criticized peers and their parents' $1 \mathrm{G}$ peers who still tried to avoid contacts with the new culture:

All [immigrant] groups should have social contacts with the Italian counterpart otherwise they go about ghettoizing. Then it's over. You cannot blame others if you did not take the first step in the right direction (Neri, Albania, 2G, F, 25).

Learning Italian was considered the first step in the right direction, because "You live in this society, you should understand it, and do not lock yourself in your house" (Sadika, Morocco, 2G, F, 23).

Acculturation across domains. Finally, the importance attributed to different life domains is another aspect of the acculturation process that was differently addressed by Moroccans and Albanians participants. Religion, for example, was immensely important to Moroccan interviewees, probably more so than Albanians because the latter tended to be Christian, have a pragmatic view on religion, to consider it as a private matter that does not interfere with social relations, or in some cases also had accepted the receiving society's religious customs (Romania, 2011). Moreover, they come from a tolerant multireligious society, where Orthodox Christians are used to living side by side in peace with Muslims (IPSOS, 2011).

For many Moroccan immigration, religion, along with language and other traditions, 
let immigrants preserve their original culture, to be "tied", to not "get lost" (Omar, Morocco, 1G, M, 30). But to be a practicing Muslim in a non-Muslim country also affected other life domains, sometimes give rising to a conflict with or a separation from the other groups. However, once again, the actual impact depended on the immigrants' personal efforts to endorse both their religious customs and traditions and the social demands of the receiving society, as this woman exemplified:

I always attended my [Italian] husband's family party, and I never say: 'I don't want to eat pork'. For me, it is disrespectful to them, I try to take that piece off the dish without being noticed, and not saying: 'Oh no, it's my religion!' (Abida, Morocco, 1G, F, 42).

Although some believed that a real integration between Italian culture and Muslim traditions is possible, others highlighted that adherence to Islamic rules (e.g., wearing a veil) can have discriminatory outcomes. Some of our interviewees (especially $1 \mathrm{G}$ ) defended the perspective of the receiving society:

Some friends of mine have difficulty in finding a job because of their veil... But it's right: you can't work as waitress with the veil, you can't go to night club with veil. I can understand. Now even in Morocco you are allowed to work with the veil! (Fatima, Morocco, 1G, F, 27).

Unlike Moroccans participants, Albanians did not mention religion as a very significant domain in their life, rather highlighting that a successful integration mainly revolved around the compliance with the law and rules of the receiving community (e.g., "People who obey the law of the country where they live can enjoy their life there. This is important to me..." - Drejta, Albanian, 1G, F, 61), the chance to attain a valuable job position, and the possibility to attain extended social relationships beyond the ethnic enclave. These participants clearly associate "real" integration to social mobility and social status. However, full integration still seemed a distant dream for many of them, as this young Albanian affirmed, "I feel like a black swan here, because we are really few, I mean the foreign people who are really integrated and have a regular job, not the usual work as 
in-home nurses" (Neri, Albanian, 2G, F, 25).

U.S. context. Most $1 \mathrm{G}$ and $2 \mathrm{G}$ immigrants in the U.S. described a preference for a strategy of integration; most immigrants desired to simultaneously maintain parts of their culture, while at the same time adapting skills to navigate within the U.S. context. In speaking about members of her Latinx immigrant community, a $1 \mathrm{G}$ immigrant expressed: I think that they have to find a middle ground where they're comfortable being in a different place, but with enough of something that's familiar if that makes any sense. They have to find what they're comfortable with, you know, by combining the United States society with whatever society they came from (Daniela, Ecuador, 1G, F, 20).

Strategic integration. As with the Italian immigrant participants, for the majority of $1 \mathrm{G}$ and $2 \mathrm{G}$ immigrants, integration was strategic; most described the need to adopt parts of the receiving community's culture in order to: (1) get their basic needs met (e.g., learn the language in order to buy needed products); (2) move themselves forward in order to obtain a better life (e.g., obtain information about resources, get citizenship); and (3) become accepted and not viewed as outsiders in the community. One important strategy immigrants utilized to achieve integration was interacting and developing relationships with receiving community members. One $2 \mathrm{G}$ immigrant emphasized this point, indicating that spending time and establishing relationships with Americans:

[It] is important because it would help them [the immigrants] [be more] acculturated yeah and be more accepted you know cause that's how we get accepted when we start acting like them, when we start thinking like them. Once we don't you know then we're, you know, like outsiders (Carlos, Peru, $2 \mathrm{G}, \mathrm{M}, 30)$.

Relatedly, immigrant perspectives also highlighted that, regardless of theory, in real life, the acculturation process was not seen as bidirectional and that often the onus was placed on the immigrant to change, even by immigrants themselves. For example, one interviewee described:

I mean the least we can do in this country is to learn the language. You know, we ask for things that 
we have to give things before we receive things. You know? We have to live by the rules, the United States' rules (Tomas, Peru, 1G, M, 37).

Although it was a goal, many Latinx participants felt that integration, in actuality, was difficult to achieve. Similar to Italian, and particularly the Moroccan 1G, participants, U.S. immigrants often feared losing their own culture and becoming "Americanized" within the acculturation process. One interviewee remarked:

Do immigrants have anything to lose [from interacting with U.S.-born people]? Probably losing our culture, our sense - you know some people become very Americanized and they forget how to behave or how it is back at home. They just forget everything (Gloria, Peru, 1G, F, 21).

Despite this difficulty, acculturation in at least some spheres was seen as crucial, and while most $1 \mathrm{G}$ and $2 \mathrm{G}$ immigrants were not as explicitly critical of their peers for being separated as were their Italian counterparts, the majority U.S. immigrants expressed concern for these decisions. Daniela explained her worries of separation:

I know that [immigrants] want to keep something from their home with them but ... I think that if they want to be happy here I think that they have to get used to the way things are here. And of course they can try to bring things in from their own familiar things, but they can't always be so stuck in what they used to have. (Ecuador, 1G, F, 20)

A few participants, however, were more harshly critical, particularly this $2 \mathrm{G}$ immigrant: We have to be aware that we are invading other people's territory, we are coming into a new country. I don't like Spanish people who are like 'oh we're not going to learn English because there's a lot of Spanish people around.' ... America is an English country, we speak English here.... they're coming to America so I think it's very important that they... learn this new culture.... We can't just invade it with our belief and our system because ...we feel comfortable, we also have to respect ... American's belief and system. (Carmen, Panama, 2G $, \mathrm{F}, 19)$

Acculturation across domains. While there was some range of perspectives on

\footnotetext{
${ }^{9}$ While Carmen had actually not immigrated until age 9 , she came here to live with an aunt who had been in the country for years, and described her upbringing as mainstream to the U.S., and considered herself $2^{\text {nd }}$ generation rather than $1^{\text {st }}$. We treated her interview as such in keeping with her desire and unique circumstances. For more on the fact that the lines separating immigration status and acculturation strategy are not as clear as often theorized, please see the discussion.
} 
acculturation, most $1 \mathrm{G}$ and $2 \mathrm{G}$ immigrants in the U.S. believed that some level of integration with the receiving community, particularly within the public and interpersonal domains, was important for survival in terms of acceptance, belonging, and in navigating public spheres. In particular, most $1 \mathrm{G}$ immigrants spoke about cultural maintenance in private domains, but discussed the need for integration if not assimilation through cultural change in public domains. This shift in acculturation across domains was similar to the way that Italian immigrants described religion, and all U.S. immigrant participants spoke frequently of this distinction. As the above-quoted $2 \mathrm{G}$ immigrant described:

\footnotetext{
With immigrants they're really deep into their environment while you're at home, but when you go out to school and stuff like that, there's like this whole new environment you're in like this whole American environment you're in, then... at home you have to be one way, and then at school you have to be another way (Carmen, Panama, 2G, F, 19).
}

Language was another example of the role domain distinction plays between cultural maintenance and change. Both $1 \mathrm{G}$ and $2 \mathrm{G}$ Latinx immigrants saw the cultural maintenance of language as most appropriate within private domains such as the home. While English was the lingua franca of social mobility, speaking one's native language in other spheres provided support, belonging, and helped to shape identity. Julissa explained:

\footnotetext{
When I'm here [in an immigrant-serving workplace], I'm speaking Spanish all day... I just feel good, like I feel comfortable... [elsewhere] I had to try to speak more like an American because my accent would be an issue... people would be like 'what are you saying?'... There was always like a sense of... holding back... you have to please them... language... not only provides you a way to talk in your native tongue... It's kind of like you're protected" (Julissa, Puerto Rico, 1G, F, 34).
}

\section{The Acculturation Process from the RCMs' Perspectives}

Italian context. The perspective of RCMs on immigrants' acculturation was generally seen to emanate from an ethnocentric perspective as the majority-dominant group, which expected newcomers to exert effort to willingly adapt to the dominant ethnocultural beliefs and attitudes of the country. For Italian participants, regardless of their 
degree of contact, immigrants' adaptation was a matter of rules:

If you want to live in Italy, you must live accordingly to our rules, correct or wrong, they are the rules that we are given. If I go to live in any other State, I'll have to do the same.... I freely choose to go there and I must undergo (Luisa, Italy, LC, F, 43).

In fact, adjustment was seen as a necessary and inevitable process that applies to whomever decides to settle in a country (or region) different from that of their birth. As Luigi stated, "When I arrived from Southern Italy, I adapted to this community. Or you do like that, or you go away, no other solution. They must do like that. Otherwise they have to stay at their country" (Luigi, Italy, HC, M, 60).

Unidirectional acculturation. Both $\mathrm{HC}$ and LC RCMs viewed the adjustment to the new cultural context as a unidirectional process, mostly based on immigrants' efforts. In fact, although the vast majority of the Italian interviewees expressed their explicit agreement with the integration of immigrants into Italian society, the implicit request was for assimilation, as it is clearly conveyed by the following statement:

If immigrants are willing to embrace our culture, then there are good chances [that they integrate]. If they don't keep maintaining their habits at any cost or regardless of the situation, and they make their own efforts, then there are good chances (Marco, Italy, LC, M, 28).

For some of our participants, this process was justified by the "moral superiority" of Western values and traditions, as this LC participant affirmed:

The great values of freedom can be mediated but not neglected. In any case, people who want to be part of our community must accept our reference values: the female issue, but also others. Democracy is our, centuries old, pathway. These are our fundamental values. Immigrant can arrive and say: 'I don't believe in democracy!' Ok, but pay attention: you are in a community that has this value as reference (Carlo, Italy, LC, M, 56).

Domain distinctions. The Italians participants were more likely to accept immigrants' willingness to maintain their cultural traditions if it was restricted to private domains. This was perhaps most apparent in the discussion of religion, which is a very 
sensitive area of the immigrant-RCMs relationships, especially when the religion in question is Islam:

You must adapt to the way of the place where you stay. Then, outside of the school, at your home, you can do what you want. But you must adapt... for example, I can't accept burqa. I wouldn't accept the crucifix either (Paolo, Italy, LC, M, 34).

A complicating factor in any attempts to separate Islam into private and public domains is that it outlines rules the faithful should follow regardless of domain - from prayers and daily devotions, to gender relationships, food, and clothing (Watt, 1996.) While some RCM participants saw this as demanding mutual respect and consideration, as highlighted here, "If I let you wear burqa, you can't remove the crucifix... You come to my house and you must have respect for my religion, and I'll have for yours" (Piero, Italy, HC, M, 43). Others saw the impact of Islam on different life domains as clashing with the practical needs of everyday life in a secular but Catholic country. As this 73-year-old man stated:

It is important that they learn and accept our rules, obviously without going against their religion....

I'll teach them that they can't stop working at $4 \mathrm{pm}$ to pray towards the Mecca. You'll get used to pray in the evening or in the morning: if you work in a company [you] cannot do that, you have to get used to this, otherwise nobody will employ you (Mario, Italy, BC, M, 73).

Overall, integration appears to still be a hard goal to reach, and the role of immigrants in Italian society is described by most as marginal and often merely instrumental, as the following excerpts demonstrated: "When he is of use, the immigrant works [i.e. fits in]. It's not a real integration" (Maria, Italy, HC, F, 50). "Immigrants do work that Italians don't want to do any longer”' (Antonio, Italy, HC, M, 23).

LC views of acculturation: “Just a matter of time”. Some differences among HC and LC participants appeared in the way they believe the acculturation process should occur, and many of these could be seen to emanate from the LC participants lack of contact with immigrants, which gave them an abstract and often shallow view of acculturation. 
Their lack of personal experiences could be seen to cause them to resort to stereotypes and prescriptive opinions about what immigrants should do once they settle in the receiving society. A second outcome of the lack of personal experience among LC participants was that they frame acculturation in a naïve, un-problematic way, as something that eventually happens as merely a "natural" consequence of time passing. As one participant explained, "It is not a matter of importance, it's actual! It's a physical and cultural trend. Some people think that we should stay locked in a castle but it's not like that... it's just a matter of time!” (Giulia, Italy, LC, F, 43). Overall, LC participants tended to consider acculturation as a simple, unified process that is not impacted by domains or contexts. Their view was also one-sided, as it requires change solely on the part of immigrants, who are requested to rid themselves of their habits, customs, rules, and values, and to adhere to the culture of the receiving country, both in the private and public sphere.

\section{HC views on acculturation: Reciprocity, bidirectionality, and positive results.}

Slightly differently, HC participants often endorsed cultural pluralism and highlighted how immigrants' cultural maintenance contributes positively to their integration, thus viewing that maintenance of cultural heritage as a priority and universal value, as in this case:

Each aspect of a culture should be preserved. My local culture should be preserved, the culture of Salento, a lost language like Griko should be maintained.... And I think it's important that also the other cultures are maintained, the culture of immigrants who live in our same territory (Leo, Italy, HC, M, 28).

Also, HC participants admitted that RCMs and immigrants can adjust to each other differently in different domains (e.g., values and traditions, or work), "To be mixed means a reciprocal knowledge of everybody.... If you pray on your prayer rug close to me while I'm eating a ham sandwich, it's fine. Nobody has to be upset"' (Sara, Italy, HC, F, 42). HC participants seemed to approach cultural diversity in a variety of ways: on the one hand, because, unlike the LC participants they had prior contact with immigrants, they grounded 
their view in this personal experience. By recalling positive concrete examples, they were able to connect ethnicity to specific individuals or groups, and to frame the acculturation processes according to personal or group ethnic characteristics. The first excerpt, below, exemplifies the use of an individual anchor, and the second, a group anchor:

When I was a child, foreigners were hated. People said: 'Foreigners bring crime'. It could be true in certain cases, but I know a man from Albania, he was a neighbor, who immigrated with his family because of the war in Kosovo.... When I met that person, he was absolutely not belonging to that category. He was... he is a trustworthy person (Antonio, Italy, HC, M, 23).

Actually, Africans are friendly, they are more inclined to meet the local people. There are a lot of mixed couples, Africans and Italians, also a friend of mine had a baby with a man from Senegal, they got married. They [the Africans] easily integrate into the community, while keeping in touch with their families of origin (Vera, Italy, HC, F, 48).

While some of our HC participants in Torino did note examples of separation that they viewed as negative, these were directed at other cultural groups than the Moroccans who were the focus of this study. On the whole HC Italian participants noted only positive personal experiences and support of immigrants as bringing personal, cultural, and social enrichment to their receiving community. As we will talk about more in the discussion, we can't entirely rule out that this may have been the result of selection, volunteer, or social desirability bias, however, it seems that for some HC Italian participants, this positive personal experience makes it difficult to grasp other more nuanced and potentially problematic details of ethnicity and culture and/or to perceive the problems associated with intercultural encounters, insofar as the general frame of their discourses is based on entirely positive assumptions about both the immigrants and the receiving society.

U.S. context. Similar to U.S. immigrant interviewees, U.S.-based low contact (LC) and high contact $(\mathrm{HC})$ receiving community participants did not describe a bidirectional acculturation process. Rather, LC and HC participants placed the onus on immigrants to 'assimilate' to U.S. culture. As one LC U.S. born participant described, "When you're ever 
going to another country... I think you should... keep as much of your own [culture] as you want... But I think [it is] probably a good idea to pick up [the culture of] wherever you live" (Ryan, U.S., LC, M, 35).

Further, from the perspectives of LC and HC participants, the extent to which immigrants should adapt ranged from integration to complete assimilation. In particular, English proficiency and interacting with receiving community members were the most frequently cited behavioral strategies that immigrants should use to integrate into U.S. society. As one participant noted:

Things that [immigrants] can do [to become a part of U.S. society] is first of all, learn English and maybe... become a part of the communities that are... more than just from their own culture. You know whether it's join a church or join a sports team or some kind of club or activity and really just get to know people from American culture. Like once you get to know some, you get to know them and they get to know you, you already become a part of their community (Jennifer, U.S., HC, F, 24).

While almost all LC and HC participants described the need for immigrants to change their norms and behaviors, the few participants who mentioned the possibility that the receiving community would change as a result of immigrant integration into U.S. society expressed resistance to this idea. As one participant described:

So it's, the mindset ... that some things are truly ours, and this is our community. But because you're here and you have that much power...[it] feel[s] like you're being bullied into taking on their culture when you didn't want to (Yvonne, U.S., LC., F, 57).

Immigrant cultural maintenance: Broad but domain specific. Both LC and HC

U.S.-born participants described immigrant cultural maintenance in broad ways that included components of language, food, history, tradition, values, art, religion, appearance/dress, among others. At a minimum, most acknowledged the importance of cultural maintenance. As one participant described, "I think it's important... for immigrants... [to] maintain some cultural identity, um but I think that cultural identity can um be woven into a collective fabric rather than be a barrier" (Deb, U.S., HC, F, 39). As 
this participant alluded to, despite some support for cultural maintenance, many receiving community members preferred that immigrant cultural maintenance operate in private domains rather than public domains. Specifically, many participants suggested that cultural maintenance should not occur at the expense of immigrant's engagement with receiving community members in the public domain. As one participant described:

Like language, and uh food, and like other cultural situations like that, I think it's good to have a variety... So I guess I want that to be preserved... I think you also want to like pick up enough to... be able to interact with other communities... you're going to do whatever meets your needs... But I think you kind of, probably a good idea to pick up [the language] wherever you live (Ryan, U.S., LC, $\mathrm{M}, 35)$.

In another related example, some U.S.-born participants explicitly rejected the idea of changing their behavior in order to interact with immigrant's cultural practices in public domains. As one participant emphasized, "if I want to learn their language and their culture and things from their country, I want to do it there, I don't want it shoved in my face here" (Felicia, U.S., LC, F, 58).

Notably, however, LC and HC participants in the U.S. responded positively to immigrant cultural maintenance in the public domain when it was inclusive or seen to benefit RCMs, such as at ethnic festivals or restaurants. When asked how valuable it is for immigrants to maintain their cultural identity, one participant responded, "It's pretty important, highly, yeah, definitely. Especially, it's really good for um, us, 'Americans.' For instance, festivals like this [Latino Festival]" (Sean, U.S., LC, M, 33).

HC \& LC attitudes towards acculturation: General agreement. In comparison to Italian $\mathrm{HC}$ and $\mathrm{LC}$ respondents, there were little to no differences between $\mathrm{HC}$ and LC interviewees in the U.S. in regards to their outlooks on acculturation strategies and attitudes. Some LC participants more strongly suggested that immigrants should fit in and assimilate into U.S. society, compared to HC interviewees. In some cases, perhaps due to 
increased contact with immigrants, $\mathrm{HC}$ participants seemed to better understand immigrants' experiences, and expressed more empathy for their acculturation experiences in the U.S. Generally, though, both LC and HC participants expressed conflicts between real and ideal acculturation, and seemed to comprehend challenges maintaining and changing cultures in public and private domains. A HC participant described:

\footnotetext{
Immigrants made America what it is ... We're a melting pot, we're all immigrants.... Without immigrants, we're not American society anymore... but at the same time... in parts of the U.S. where we have so many Hispanic immigrants, they don't even care to assimilate to American culture, and by American culture I mean speak English... go to American movies or eat American food, they keep their own culture... I feel like some of them try really hard to assimilate... others don't try as hard and I feel like maybe the government and society... is proud of the people who try hard and looks down upon the people who don't... not that we all have to be ... cookie cutter people, we don't all have to be the same but also you can't expect to immigrate here and not change a little (Jennifer, U.S., HC, F, 24).
}

\section{Discussion}

Our study aimed to deepen understanding of the acculturation process, both from the perspective of immigrants and of the receiving societies, by considering different groups of immigrants ( $1^{\text {st }}$ and $2^{\text {nd }}$ generation Moroccans, Albanian and Latin-Americans), of receiving community members (RCMs; with high and low immigrants contact) and different acculturation settings (Italy and U.S.). Some results highlight the culture- and context-dependent nature of acculturation, while other findings underline the presence of common experiences and attitudes.

On the whole, all immigrant groups agreed that the main way to achieve integration is to learn the local language and develop relationships with RCMs. Notably, this finding may have been impacted by all immigrant participants being proficient in the primary language of their receiving communities. Relevant differences in how this was enacted did emerge across ethnic groups. For example, both Albanians and Latin Americans tended to 
focus more on how a measure of successful integration can lead to increased social status as seen in majority community access, education, and employment. However, they pointed out different strategies for achieving integration: while Albanians stressed the relevance of respecting the rules of the receiving country, Latin Americans mostly emphasized the importance of language acquisition and establishing relations with RCMs.

As expected, the immigrant generation was seen to shape the acculturation process. In keeping with the literature (e.g., Ward, 2013), 2G immigrants experience a multi-faceted sense of identity that was interpreted more as a resource than as a limitation. On the other hand, $1 \mathrm{G}$ immigrants reported several problems in re-defining their personal and social identity after migration, which led to a range of feelings, from loss to an identity enrichment. These results partially challenge previously literature that has found the burden of acculturation and identity shaping (Birman \& Trickett, 2001) and the need to balance hyphenated identities and integration (Bélanger \& Verkuyten, 2010) to be more problematic for $2 \mathrm{G}$ versus $1 \mathrm{G}$ immigrants. Although our study was not focused specifically on this, some results that our $2 \mathrm{G}$ participants benefit from utilizing a more dynamic, openended process of "situated identity" (Weinrich, 2009).

Finally, our immigrant interviewees appear quite cognizant of the distinction between public versus private life domains. In other words, immigrant participants generally believed that the space for cultural maintenance is mostly the private one, while the public space involves the accession to the dominant cultural model - whether that be enacted adherence or real acceptance. Specifically, this perspective on acculturation, i.e. public assimilation (or integration) and private separation, seemed to be shared by our participants regardless of their immigration status, country of origin or settlement, or degree of contact. Interestingly, there were a few $2 \mathrm{G}$ Albanian respondents who seemed to be less inclined to distinguish between the private and the public sphere showed what the 
literature typically considers an integrative acculturation strategy - keeping aspects of both their culture of origin as well as adopting aspects of the receiving culture and applying these to all of their life domains.

While the overall acculturation process was the same, the salience and significance of the different acculturation domains (e.g., work, family, religion, social relationships, etc.) varied according to immigrant groups and receiving societies. Religion spontaneously converged as a domain of increased salience for RCM and immigrants alike, but played a particularly important role for both generations of Moroccan immigrants. This result was to some extent expected. Indeed, Morocco is a mono-religious country where Muslims are the majority. Their migration to Italy leads them to be both an ethnic and a religious minority (Gattino, Miglietta, Rizzo, \& Testa, 2016), which is not a concern shared by Albanian or Latinx immigrants whose immigration could be seen as conferring upon them a majority status when it comes to religion. This distinct cultural difference may have led Muslim Moroccans to highly value their religious identity and see it as a source of meaning making, cultural continuity, and social support (Güngör, Fleischmann, Phalet, \& Maliepaard, 2013; Ysseldyk, Matheson, \& Anisman, 2010). As Moroccans as a group were less likely to focus on social integration and social mobility, this does raise a question as to whether coping with religious cultural maintenance puts stress on reserves that might otherwise be directed elsewhere in the acculturation process. It seems possible this represents a risk occurring when any factor sets one's group apart, rather than being something that is silently shared. Overall, however, to some extent, this shows how domains, their salience, and meaning are "co-constructed" between the immigrants and the receiving society.

Not surprisingly, RCMs participants, both in Italy and U.S., seem to place the onus of responsibility on immigrants to adapt to the new society, particularly by learning the 
language (U.S.) and by adopting the rules (Italy) of the receiving community. On the whole, RCMs seem to confirm a preference for immigrants to assimilate, as already highlighted in the literature (Mancini \& Bottura, 2014; Navas et al., 2005; 2007), while also accepting immigrants' cultural maintenance in private domains (Italy) or when it has some limited advantages for the receiving community (U.S.), like a cultural festival or restaurant, that adds to but doesn't change the RCM's sense of community. Moreover, an idea of "subordinated inclusion" (Cotesta, 2009) emerges, especially among the Italian respondents. This idea refers to the possibility that immigrants are included and accepted selectively and in a functional way - in some areas of social relations, typically in particular jobs, but are excluded from benefitting from other fundamental rights.

As expected, some differences in perspective also appeared with respect to the level of contact with immigrants reported by our RCMs. HC RCMS were more likely to express feelings of empathy for immigrants they personally knew, thereby suggesting that direct contact with immigrants works can have a positive impact on intercultural relationships. Following the more recent revisions of contact hypothesis (Pettigrew \& Tropp, 2008; Pettigrew, Tropp, Wagner, \& Christ, 2011), one-to-one contact has been found to reduce anxiety and, in turn, increase empathy. These affective factors can strengthen the cognitive mediators (e.g., perspective taking and knowledge) that are likely to reduce prejudice. The contact that all of our participants refer to is typically of an interpersonal nature, based on occasional meetings with immigrants at work, in schools or at community events. When this contact is not fully actualized into real relationships or menacing in stereotypical or abstract ways, as in LC RCMs, or it is idealized as in some of our HC RCMs, these experiences, both imagined and real may play a major role in shaping an unrealistically and naively positive, ambivalent or hostile attitude towards immigrants' integration. In other work with this data set, we were able to explore the perceived impact of the media on 
narratives of immigration and found this as one concrete example of how, in the absence of meaningful and real interaction, massaged and second hand "contact" can have a deleterious effect on intergroup relationships and true acculturative opportunities and experiences (Authors, under review).

Despite the different settings and ethnocultural groups involved, our analysis found a number of commonalities. First, both immigrants and RCMs found integration to be the most effective strategy that immigrants could use to interact positively with their new cultural environment. However, both groups understood integration to be a soft assimilation, where the newcomers are required to adopt the host society's culture, especially in public domains.

Second, acculturation was expected to be, an unbalanced process. Both immigrant and RCM participants perceived acculturation as a process of accommodation, in which immigrants are charged to adapt to their new contexts, while the bidirectional nature of acculturation is mostly neglected by both groups. This shared conception of the acculturative process seems on the surface to have a positive outcome, namely harmonious community agreement. However, the status and power differences between dominant and non-dominant cultural groups (Bourhis et al., 1997) are highly relevant here. Indeed, from the dominant side, this seemingly voluntary agreement can imply (or more so explicitly articulate) an ethnocentric attitude (Sumner, 1906) and/or autochthony (Martinovic \& Verkuyten, 2013) - the idea that the cultural values of receiving societies are superior to those of the immigrants'. From the non-dominant side, such a match can imply the acceptance of a subordinate group status, the withdrawal to a valued niche, or a preference for either individual social mobility strategies or social creativity strategies (Tajfel \& Turner, 1979). On these bases, it would be more fitting to describe this "agreement" as creating a community that avoids a conflict rather than one that is genuinely harmonious. 
In addition to the unidirectional nature of acculturation, its individual nature also should be highlighted as one of the attributes that our participants often used in reference to immigrants' experience in host societies. Needless to say, framing acculturation as an individual effort based on immigrant responsibility leaves in the shadow the conspicuous and undeniable role that socio-political and collective factors (e.g., law, racism) play in multi-cultural societies.

Overall, our study highlights the need to go beyond models that present acculturation as a unidirectional, universal process made of fixed phases that occur regardless of the contextual cultural, social, and political factors. Particularly, our study shows that, unlike what the most commonly used psychosocial models suggest, the boundaries between acculturation strategies, life domains, and even immigration statuses are both blurred, and they emerge through an interactive process that connects the expectations and attitudes of the receiving societies with that of the immigrant groups.

\section{Limitations and Implications for Research and Practice}

Although the main strength of this study is its cross-national and culturally situated nature, this aspect could also represent its most relevant limitation. Indeed, as anyone who has done cross setting/ cross cultural research can attest, creating consistent data collection and analytic protocols across geographic, linguistic, and cultural differences is a challenging process, which is bound to introduce inconsistencies and potential translational (both linguistic and scientific) errors, regardless of the amount of care taken. These are shared issues in any study of context, meaning, and purpose, and care was taken to ensure that they were as adequately addressed as possible.

There were also a number of questions that we either could not or did not ask during data collection or in this presentation of our findings. The complicated nature of this study design, the length of the interview protocol, and amount of qualitative data that resulted 
meant that some potentially important questions, such as how language ability might impact this process, the meaning of subjective self-reporting of level of contact, and the role of legal status were not included. Other issues such as the role of gender; more specific racial/ethnic immigrant identities; education level; or the cultural and/or linguistic characteristics of our RCM participants, which may have impacted their views on the preeminence of the receiving culture and their unidimensional views of acculturation were not explored here due to the reporting limits of any one publication. We leave these important questions for the next study or subsequent analysis as appropriate.

Although in the end, the number of participants in each setting was not equal, this did not unduly impact the development of themes, coding, or results as in qualitative work it is not the mean or even modal finding that is important but rather creating a finding narrative that describes all expressed experiences in a holistic way.

Despite these limitations, by sharing data and findings about the experience of acculturation across different countries, ethnic groups, and RCMs, we were able to engage in a unique transversal analysis that uncovered novel differences and commonalities, which add to a more contextualized understanding of the acculturation process.

Several theoretical and practical suggestions can be drawn from this study. On the theoretical level, our study confirms that acculturation is a complex, situated, and dynamic process, with a multifaceted and interactive nature (Doucerain, Dere \& Ryde, 2013; Ward, 2013). Consequently, it seems necessary to adopt a critical perspective on acculturation (e.g. Cruz \& Sonn, 2011; Rudmin, 2003), paying attention to "the symbolic and meaningproducing nature of sociocultural realities" (Chirkov, 2009, p. 88).

More flexible models, able to overcome the individual and linear nature of acculturation, as well as the idea that achieving integration is the common and most beneficial aim (Ward, 2013), should be explored. Particularly, acculturation should be 
genuinely conceived as a continuously negotiated process (Bhatia \& Ram, 2009) and models should be designed to attend to the structural forces and psychosocial factors as well as to the cultural and political specificity of the settings in which acculturation occurs and of the groups involved. Moreover, the study of social dynamics in real group relations must consider the social power differentials that characterize societies (Dixon \& Levine, 2012). To these ends, qualitative research should be encouraged to best understand the actual and ever changing contextualized realities and needs of both immigrants' and receiving communities. This issue of 'ever changing realities' is particularly relevant to this study, whose data collection began prior to the Syrian refugee crisis that has increased antiimmigrant sentiment across the world, and whose analysis began before the 2016 U.S. presidential campaign and election, which is bringing about radical change in the public discourse and policies surrounding immigration, and continues to threaten even more.

On the practical side, our study suggests that immigration policies, when written to aid the immigrant/receiving community experience, should avoid conceiving of immigrants as one homogeneous category. Similarly, receiving societies are varied in ethnic, linguistic, and other background (Bourhis, Montaruli, El-Geledi, Harvey, \& Barrette, 2010), but also contain RCMs with varied expectations, experiences, and degrees of contact with immigrants, as well as varied levels of power. Our findings suggests that policies and practices that are more sensitive to the cultural, ethnic, and power differences both between and within immigrants and RCMs could have more effective and positive results.

Moreover, it must be considered that the consensual sphere of everyday interaction and the reified sphere of state institutions (Andreouli \& Howarth, 2013) largely influence each other. The consensual frame of acculturation, which presents an unbalanced, naively "voluntary," and individual process, should be carefully avoided in policies and intervention programs, which instead should invoke and activate the responsibility of all 
the actors involved. Politicians and professionals operating in the field of multicultural relations should also consider that the impact of intergroup inequalities is not always promoted only by dominant groups (Dixon \& Levine, 2012). As we saw, non-dominant members also showed an acceptance of certain inequalities in cultural expression (e.g., cultural maintenance only in the private sphere) that likely play a role in hindering the redistribution of social power (Jost, Pelham, Sheldon \& Ni Sullivan, 2003) and ultimately real and positive intercultural communities.

One possible solution is to create more productive interaction between RCMs and immigrants that can occur in a more neutral institutional and/or community setting. This creation of shared space, unconnected to one group or the other, could circumvent the seemingly shared demand for public assimilation. As Pettigrew and Tropp (2006) have reported multiple times it is not just contact but repeated contact in conditions of equal status and shared goals that makes an impact. The creation of such spaces for immigrant/receiving community interaction could shift the focus from an onus on the efforts of individuals to "belong" to the creation of group status symmetries; interrupting these experiences of assumed asymmetries may also redirect the outcomes from social injustice to shared social justice. On the whole, the current study supports the importance of context sensitive, community-based interventions, involving both formal (e.g., school, services) and informal (e.g., cultural and religious organizations) resources and settings that can not only reduce the negative effects of immigration (e.g., acculturative stress, Tummala-Narra, 2015) but enhance the possibility of building a genuine multicultural society, incorporating social justice principles (APA, 2012) in the framing and management of the acculturation process. 


\section{References}

Acosta, Y. D., \& De la Cruz, G. P. (2011). The foreign born from Latin America and the Caribbean: 2010 (pp. 1-6). US Department of Commerce, Economics and Statistics Administration, US Census Bureau.

Allievi, S. (2014). Immigration, religious diversity and recognition of differences: the Italian way to multiculturalism. Identities, 21, 724-737. doi:10.1080/1070289X.2013.828623

Allport, G. W. (1954). The nature of prejudice. Cambridge, MA: Addison-Wesley.

Andreouli, E., \& Howarth, C. (2013). National identity, citizenship and immigration: Putting identity in context. Journal for the Theory of Social Behaviour, 43, 361-382. doi:10.1111/j.1468-5914.2012.00501.x

American Psychological Association, Presidential Task Force on Immigration. (2012).

Crossroads: The psychology of immigration in the new century. Retrieved from http://www.apa.org/topics/immigration/report.aspx

Arends-Tóth, J., \& Van de Vijver, F. J. (2003). Multiculturalism and acculturation: views of Dutch and Turkish-Dutch. European Journal of Social Psychology, 33, 249-266. doi:10.1002/ejsp.143

Belanger, E., \& Verkuyten, M. (2010). Hyphenated identities and acculturation: Secondgeneration Chinese of Canada and the Netherlands. Identity: An International Journal of Theory and Research, 10, 141-163.

Berry, J. (1970). Marginality, stress and ethnic identification in an acculturated aboriginal community. Journal of Cross-Cultural Psychology, 1, 239-252.

Berry, J. W. (2005). Acculturation: Living successfully in two cultures. International journal of intercultural relations, 29, 697-712. doi:10.1016/j.ijintrel.2005.07.013

Berry, J. W. (2006). Acculturation: A conceptual overview. In B. M. H. Bornstein \& L. R. Cote (Eds.), Acculturation and parent-child relationships: Measurement and 
development (pp. 13-30). Mahwah, NJ: Lawrence Erlbaum Associates Publishers.

Bhatia, S., \& Ram, A. (2009). Theorizing identity in transnational and diaspora cultures: A critical approach to acculturation. International Journal of Intercultural Relations, 33, 140-149. doi:10.1016/j.ijintrel.2008.12.009

Birman, D., \& Trickett, E. J. (2001). Cultural transitions in first-generation immigrants: Acculturation of Soviet Jewish refugee adolescents and parents. Journal of CrossCultural Psychology, 32, 456-477. doi:10.1177/0022022101032004006

Bourhis, R. Y., Moise, L. C., Perreault, S., \& Senecal, S. (1997). Towards an interactive acculturation model: A social psychological approach. International Journal of Psychology, 32, 369-386. doi:10.1080/002075997400629

Bourhis, R. Y., Montaruli, E., El-Geledi, S., Harvey, S. P., \& Barrette, G. (2010).

Acculturation in multiple host community settings. Journal of Social Issues, 66, 780-802. doi:10.1111/j.1540-4560.2010.01675.X

Bowskill, M., Lyons, E., \& Coyle, A. (2007). The rhetoric of acculturation: When integration means assimilation. British Journal of Social Psychology, 46, 793-813. doi:10.1348/014466607X182771

Bronfenbrenner, U., \& Morris, P. A. (1998). The ecology of developmental processes. In R.M. Lerner (Ed.), Theoretical models of human development (pp. 993-1028). New York: Wiley.

Buckingham, S. L. (2017). When real diverges from ideal: How person-environment fit impacts Latina/o immigrants' acculturation and psychosocial wellbeing across four states (Doctoral dissertation). ProQuest.

Buckingham, S. L., \& Brodsky, A. E. (2015). 'Our differences don't separate us': Immigrant families navigate intrafamilial acculturation gaps through diverse resilience processes. Journal of Latina/o Psychology, 3, 143-159. doi:10.1037/lat0000042 
Authors, (under review). 'You opened my mind': Latinx immigrant and receiving community interactional dynamics in the United States.

Cheung, B. Y., Chudek, M., \& Heine, S. J. (2011). Evidence for a sensitive period for acculturation younger immigrants report acculturating at a faster rate. Psychological Science, 22, 147-152. doi:10.1177/0956797610394661

Chirkov, V. (2009). Introduction to the special issue on Critical Acculturation Psychology. International Journal of Intercultural Relations, 2, 87-93.

Cook-Martín, D., \& FitzGerald, D. (2010). Liberalism and the limits of inclusion: Race and immigration law in the Americas, 1850-2000. Journal of Interdisciplinary History, 41, 7- 25. doi:10.1162/jinh.2010.41.1.7

Cotesta, V. (2009). Sociologia dei conflitti etnici. Razzismo, immigrazione e società multiculturale. [Sociology of ethnic conflicts. Racism, immigration and multicultural society]. Bari: Laterza

Cruz, M. R., \& Sonn, C. C. (2011). (De) colonizing culture in community psychology: Reflections from critical social science. American Journal of Community Psychology, 47, 203-214. doi:10.1007/s10464-010-9378-x

Dixon, J., \& Levine, M. (Eds.). (2012). Beyond prejudice: Extending the social psychology of conflict, inequality and social change. Cambridge University Press.

Doucerain, M., Dere, J., \& Ryder, A. G. (2013). Travels in hyper-diversity: Multiculturalism and the contextual assessment of acculturation. International Journal of Intercultural Relations, 37, 686-699. doi:10.1016/j.ijintrel.2013.09.007

Gattino, S., Miglietta, A., Rizzo, M, \& Testa, S., (2016). Muslim Acculturation in a Catholic Country: Its associations with religious identity, beliefs, and practices. Journal of Cross-Cultural Psychology, 47, 1-7. doi:10.1177/0022022116661244

Güngör, D., Fleischmann, F., Phalet, K., \& Maliepaard, M. (2013). Contextualizing Religious 
Acculturation. Cross-cultural perspectives on Muslim minorities in Western Europe European Psychologist, 18, 203-214. doi:10.1027/1016-9040/a000162

Immigration Statistical Report (2015). Italian National Institute of Statistics. International and Internal Migration. Retrieved from https://www.istat.it/en/archive/immigrants

IPSOS (2011). Strategies of symbolic nation - building in West Balkan states. http://www.hf.uio.no/ilos/english/research/projects/nation-w-balkan/index.html Jost, J. T., Pelham, B. W., Sheldon, O., \& Ni Sullivan, B. (2003). Social inequality and the reduction of ideological dissonance on behalf of the system: Evidence of enhanced system justification among the disadvantaged. European Journal of Social Psychology, 33, 13-36. doi:10.1002/ejsp.127

Krogstad, J. M. (2015). On views of immigrants, Americans largely split along party lines. The Pew Research Center. Retrieved from http://www.pewresearch.org/facttank/2015/09/30/on-views-of-immigrants-americans-largely-split-along-party-lines/

Kunst, J. R., \& Sam, D. L. (2013). Relationship between perceived acculturation expectations and Muslim minority youth's acculturation and adaptation. International Journal of Intercultural Relations, 37, 477-490. doi:10.1016/j.ijintrel.2013.04.007

Kunst, J. R., \& Sam, D. L. (2014). "It's on time that they assimilate": Differential acculturation expectations towards first and second generation immigrants. International Journal of Intercultural Relations, 39, 188-195. doi:10.1016/j.ijintrel.2013.10.007

Mancini, T., \& Bottura, B. (2014). Acculturation processes and intercultural relations in peripheral and central domains among native Italian and migrant adolescents. An application of the Relative Acculturation Extended Model (RAEM). International Journal of Intercultural Relations, 40, 49-63. doi:10.1016/j.ijintrel.2013.12.002

Martinovic, B., \& Verkuyten, M. (2013). 'We are here first, so we determine the rules of the 
game': Autochthony and prejudice towards out-groups. European Journal of Social Psychology, 43, 637-647. doi:10.1002/ejsp.1980

Matera, C., Stefanile, C., \& Brown, R. (2015). Majority-minority acculturation preferences concordance as an antecedent of attitudes towards immigrants: The mediating role of perceived symbolic threat and metastereotypes. International Journal of Intercultural Relations, 45, 96-103. doi:10.1016/j.ijintrel.2015.02.001

Navas, M., García, M. C., Sánchez, J., Rojas, A. J., Pumares, P., \& Fernández, J. S. (2005). Relative Acculturation Extended Model (RAEM): New contributions with regard to the study of acculturation. International Journal of Intercultural Relations, 29, 2137. doi:10.1016/j.ijintrel.2005.04.001

Navas, M., Rojas, A. J., García, M., \& Pumares, P. (2007). Acculturation strategies and attitudes according to the Relative Acculturation Extended Model (RAEM): The perspectives of natives versus immigrants. International Journal of Intercultural Relations, 31, 67-86. doi:10.1016/j.ijintrel.2006.08.002

Pew Research Center (2017). 5 facts about illegal immigration in the U.S. Retrieved from http://www.pewresearch.org/fact-tank/2017/04/27/5-facts-about-illegal-immigration$\underline{\text { in-the-u-s/ }}$

Passel, J. S., Cohn, D., \& Gonzalez-Barrera, A. (2012). Net migration from Mexico falls to zero--and perhaps less. Washington, DC: Pew Hispanic Center. Retrieved from http://www.pewhispanic.org/2012/04/23/net-migration-from-mexico-falls-to-zero-andperhaps-less/

Pettigrew, T. F., \& Tropp, L. R. (2006). A meta-analytic test of intergroup contact theory. Journal of Personality and Social Psychology, 90, 751-783. doi:10.1037/0022$\underline{3514.90 .5 .751}$

Pettigrew, T. F., \& Tropp, L. R. (2008). How does intergroup contact reduce prejudice? Meta- 
analytic tests of three mediators. European Journal of Social Psychology, 38, 922934. doi:10.1002/ejsp.504

Pettigrew, T. F., Tropp, L. R., Wagner, U., \& Christ, O. (2011). Recent advances in intergroup contact theory. International Journal of Intercultural Relations, 35, 271280. doi:10.1016/j.ijintrel.2011.03.001

Pfafferott, I., \& Brown, R. (2006). Acculturation preferences of majority and minority adolescents in Germany in the context of society and family. International Journal of Intercultural Relations, 30, 703-717. doi:10.1016/j.ijintrel.2006.03.005

Phinney, J. S., \& Rosenthal, D. A. (1992). Ethnic identity in adolescence: Process, context, and outcome. In G. R. Adams, T. P. Gullota, \& R. Montemayor (Eds.), Adolescent identity formation (pp. 145-172). Newbury Park, CA: Sage.

Portes, A., Fernandez-Kelly, P., \& Haller, W. (2005). Segmented assimilation on the ground: The new second generation in early adulthood. Ethnic and racial studies, 28, 10001040. doi:10.1080/01419870500224117

Prilleltensky, I. (2008). Migrant well-being is a multilevel, dynamic, value dependent phenomenon. American Journal of Community Psychology, 42, 359-364. doi:10.1007/s10464-008-9196-6

Pumariega, A. J., \& Rothe, E. (2010). Leaving no children or families outside: the challenges of immigration. American Journal of Orthopsychiatry, 80, 505-515. doi:10.1111/j.1939-0025.2010.01053.x

Rohmann, A., Florack, A., \& Piontkowski, U. (2006). The role of discordant acculturation attitudes in perceived threat: An analysis of host and immigrant attitudes in Germany. International Journal of Intercultural Relations, 30, 683-702. doi:10.1016/j.ijintrel.2006.06.006

Rohmann, A., Piontkowski, U., \& van Randenborgh, A. (2008). When attitudes do not fit: 
Discordance of acculturation attitudes as an antecedent of intergroup threat.

Personality and Social Psychology Bulletin, 34, 337-352.

doi: $10.1177 / 0146167207311197$

Romania, V. (2011). Farsi passare per italiani. Strategie di mimetismo sociale [Passing for Italians. Strategies of social mimicry]. Roma: Carocci.

Rudmin, F. W. (2003). Critical history of the acculturation psychology of assimilation, separation, integration, and marginalization. Review of General Psychology, 7, 3-37. doi: $10.1037 / 1089-2680.7 .1 .3$

Sabatier, C. (2008). Ethnic and national identity among second-generation immigrant adolescents in France: The role of social context and family. Journal of Adolescence, 31, 185-205. doi:10.1016/j.adolescence.2007.08.001

Salo, C. D., \& Birman, D. (2015). Acculturation and psychological adjustment of Vietnamese Refugees: An ecological acculturation framework. American journal of community psychology, 56, 395-407. doi:10.1007/s10464-015-9760-9

Schwartz, S. J., Unger, J. B., Zamboanga, B. L., \& Szapocznik, J. (2010). Rethinking the concept of acculturation: Implications for theory and research. American Psychologist, 65, 237-251. doi:10.1037/a0019330

Smith, R. (2008). Social Work and Power. Basingstoke: Palgrave Macmillan.

Stephan, W. G., \& Stephan, C. W. (2000). An integrated threat theory of prejudice. In S. Oskamp (Ed.) Reducing prejudice and discrimination, 23-45, Mahwah, N.J.: Lawrence Erlbaum Associates.

Strauss, A., \& Corbin, J. (1990). Basics of qualitative research (Vol. 15). Newbury Park, CA: Sage.

Sumner, W. G. (1906). Folkways. Boston, MA: Ginn.

Tajfel, H., \& Turner, J. C. (1979). An integrative theory of intergroup conflict. In W. G. 
Austin \& S. Worchel (Eds.), The social psychology of intergroup relations, (pp. 3348). Pacific Grove, CA: Brooks/Cole.

Taylor, D. M., \& Lambert, W. E. (1996). The meaning of multiculturalism in a culturally diverse urban American area. Journal of Social Psychology, 136, 727-740. doi: $10.1080 / 00224545.1996 .9712249$

Tseng, V., \& Yoshikawa, H. (2008). Reconceptualizing acculturation: Ecological processes, historical contexts, and power inequities. American Journal of Community Psychology, 42, 355-358. doi:10.1007/s10464-008-9211-y

Tummala-Narra, P. (2015). Ethnic identity, perceived support, and depressive symptoms among racial minority immigrant-origin adolescents. American Journal of Orthopsychiatry, 85, 23-33. doi:10.1037/ort0000022

United Nations, Department of Economic and Social Affairs, Population Division. (2016). International migration report 2015: Highlights (ST/ESA/SER.A/375). Retrieved from http:// www.un.org/en/development/desa/population/migration/ publications/migrationreport/docs/MigrationReport2015_ Highlights.pdf

United Nations Population Fund (2015). Migration. Retrieved from http://www.unfpa.org/

Ward, C. (2013). Probing identity, integration and adaptation: Big questions, little answers. International Journal of Intercultural Relations, 37, 391-404. doi:10.1016/j.ijintrel.2013.04.001

Ward, C., Fox, S., Wilson, J., Stuart, J., \& Kus, L. (2010). Contextual influences on acculturation processes: The roles of family, community and society. Psychological Studies, 55, 26-34. doi:10.1007/s12646-010-0003-8

Watt, W. M. (1996). A Short History of Islam. Oxford: Oneworld Pub.

Weinreich, P. (2009). 'Enculturation', not 'acculturation': Conceptualising and assessing identity processes in migrant communities. International Journal of Intercultural 
Relations, 33, 124-139. doi:10.1016/j.ijintrel.2008.12.006

Yakushko, O., \& Morgan-Consoli, M. L. (2014). Gendered stories of adaptation and resistance: A feminist multiple case study of immigrant women. International Journal for the Advancement of Counselling, 36, 70-83. doi:10.1007/s10447-013-9191-y

Ysseldyk, R., Matheson, K., \& Anisman, H. (2010). Religiosity as Identity: Toward an understanding of religion from a social identity perspective. Personality and Social Psychology Review, 14, 60-71. doi:10.1177/1088868309349693

Zagefka, H., \& Brown, R. (2002). The relationship between acculturation strategies, relative fit and intergroup relations: immigrant-majority relations in Germany. European Journal of Social Psychology, 32, 171-188. doi:10.1002/ejsp.73

Zagefka, H., González, R., \& Brown, R. (2011). How minority members' perceptions of majority members' acculturation preferences shape minority members' own acculturation preferences: Evidence from Chile. British Journal of Social Psychology, 50, 216-233. doi:10.1348/014466610X512211 
Acculturation in the discourse of immigrants and receiving community members. Results from a cross-national qualitative study.

\section{Tables}

Table 1. Demographic and descriptive statistics for Italy and U.S. samples.

\begin{tabular}{lccccccccccccc}
\hline & \multicolumn{3}{c}{ Lecce } & \multicolumn{3}{c}{ Torino } & \multicolumn{3}{c}{ Baltimore/DC } \\
& \multicolumn{2}{c}{ Immigrant } & \multicolumn{2}{c}{ Native } & Immigrant & Native & \multicolumn{2}{c}{ Immigrant } & Native \\
\hline Generation/Contact & $1^{\text {st }}$ & $2^{\text {nd }}$ & HC & LC & $1^{\text {st }}$ & $2^{\text {n }}$ & HC & LC & $1^{\text {st }}$ & $2^{\text {nd }}$ & HC & LC \\
N & 17 & 12 & 14 & 16 & 20 & 20 & 20 & 20 & 15 & 15 & 15 & 15 \\
Gender (\% women) & 52.9 & 52.9 & 52.9 & 50.0 & 50.0 & 58 & 70 & 55 & 66.7 & 60.0 & 60.0 & 60.0 \\
Mean Age & 33.411 .8 & 25.6 & 31.6 & 31.414 .8 & 31.4 & 21 & 45.3 & 36.4 & 36.3 & 23.2 & 43.6 & 44.7 \\
SD & & 8.0 & 12.5 & & 12.6 & 2.3 & 8.7 & 16.2 & 11.3 & 4.8 & 19.3 & 19.3 \\
\hline
\end{tabular}

